\title{
Partial Versus General Compulsory Solidarity: an Experimental Analysis
}

\section{Andrej Angelovski ${ }^{1} \cdot$ Arianna Galliera $^{2} \cdot$ Werner Güth ${ }^{3,4}$ (D}

Received: 24 September 2019 / Accepted: 4 December 2019 / Published online: 20 December 2019

(c) The Author(s) 2019

\begin{abstract}
We focus on ways and means of solidarity and their more or less voluntary and involuntary character. Alternative ways of redistribution are modeled by combining redistribution as emergent from a non-discriminatory voluntary contribution mechanism, VCM, with an outside option for a "super-rich", $R$, participant to donate to VCM participants. The outsider may discriminate between participants of the VCM on the basis of information accessible at a cost to her. Inclusion in and exclusion from the VCM are involuntary while contributions in it are voluntary. How involuntary inclusion of $R$ in VCM affects her discriminatory voluntary donations and contribution behavior is explored experimentally.
\end{abstract}

Keywords Compulsory solidarity $\cdot$ Collective goods $\cdot$ Charitable giving $\cdot$ Inequality

JEL Cliassification C72 · C91 · C92 · D63 · D64 · H44

\section{Introduction}

The institutions providing the services that we identify with rule of law and the regulatory framework within which modern markets operate are state sponsored and financed by coercive taxes. In the sense of imposing regulations and

Werner Güth

gueth@coll.mpg.de

Andrej Angelovski

a.angelovski@mdx.ac.uk

Arianna Galliera

arianna.galliera@unicatt.it

$1 \quad$ Middlesex University, London, UK

2 Università del Sacro Cuore, Milan, Italy

3 Max-Planck Institute for Research on Collective Goods, Kurt-Schumacher-Str. 10, 53113 Bonn, Germany

4 LUISS, Rome, Italy 
raising compulsory contributions even the most minimal is a welfare state of sorts. Beyond the protective as a minimum welfare state all advanced legal orders also are productive states. They also ("productively") provide minimal guarantees of income that are financed by compulsory taxes.

According to ideals of substantively equal treatment under rule of law standards redistributive policies must be non-discriminatory (see Kliemt 1993; Buchanan and Congleton 2006; Oprea 2019 in this volume of HOEC).

Non-discrimination in redistributive policies suggests demogrant schemes of equal guarantees of basic income for all citizens, as are nowadays propagated in particular by the political left (see Van Parijs 1992), were favored originally by classical liberals [most prominently by Friedman (1962) with his proposal of what he called a "negative income tax"]. While their popularity is still on the ascent on the left of the political spectrum, unconditional basic income guarantees became increasingly unpopular among many liberal adherents of free markets (including those who otherwise think of Milton Friedman as their intellectual hero).

This paper acknowledges that, to the extent that it could be financed within financial constraints, redistribution via demogrant schemes is attractive. But it also acknowledges fundamental concerns about non-discriminatory compulsory solidarity as "embodied" in demogrant schemes. Taking sides with either the political left or the political right in this controversy is not among the aims of the paper. Rather than presenting conventional normative arguments it approaches certain aspects of the controversy experimentally.

The results of the experiments presented below speak to three central objections against implementing non-discriminatory (equal) basic income as "compulsory solidarity":

1. Non-discriminatory or unconditional (not means-tested) claims to basic income would induce those who are conventionally regarded as "non-deserving poor" to opt out of the labor market. Other than the adherents of unconditional basic income, the "resenters" do not regard it as a public good to help the poor regardless of the causes of poverty. Due to such widespread resentment, the claim that providing non-discriminatory compulsory solidarity amounts to a Pareto improvement is precarious at best. Moreover, the scheme might not survive at the polls in a democracy. (In view of this it is not accidental that mandatory basic "social security" which amounts to an earmarked tax is camouflaged as "social insurance" in countries like Germany).

2. Many adherents of free societies not only resent the non-discriminatory but also the coercive nature of compulsory solidarity implemented as unconditional basic income. For them solidarity has moral merit only to the extent that it is voluntary. Accepting that ought presupposes can the demand for voluntariness translates into demanding that solidarity should be voluntary to the maximum viable extent.

3. Moreover, many adherents of rule of law and free market societies believe that relying on the fundamental coercive power of the state in exercising solidarity tends to crowd out the basic proclivity of humans to help their fellows voluntarily and/or to self-help by means of voluntary associations. They would typically add 
that in free market societies in particular the super-rich-the Rockefellers, Warren Buffets and Bill and Melinda Gates types-have been and still are willing to voluntarily help the deserving poor. Since voluntary donors are legally entitled to discriminate, they can select the deserving poor in targeted ways and thus exercise solidarity more efficiently than the state sponsored compulsory solidarity schemes that under the rule of law constraints rein in discrimination by state agencies and agents.

In our comparative institutional analysis we will focus on ways and means of redistribution and their more or less voluntary and involuntary character. We will do so in terms of alternative rules and how they affect experimental laboratory interactions. More specifically, alternative ways of redistribution are modeled by combining redistribution as emergent from a non-discriminatory voluntary contribution mechanism, VCM, with an outside option open to a "super-rich" participant. The super-rich may discriminate in her redistributive voluntary donations. She can do so on the basis of information accessible at a cost to her.

We distinguish two cases of "institutional settings" as represented in the laboratory. In one case to which we refer as partial compulsory solidarity, PCS, the superrich is not a participant of the VCM but can interact with the "non-rich" participants. Her options are either granting or withholding donations which she may or may not base on information on whether the recipients are deserving or not. In the other case, to which we refer as exemplifying general compulsory solidarity, GCS, the super-rich individual participates in the VCM that distributes indiscriminately equal shares of the common pool to each participant (independent of wealth and largely independent of contributions). In GCS as in PCS, besides contributing to the common pool, the super-rich can still exercise solidarity in targeted ways.

The two precedingly sketched settings should offer some insights concerning how being involuntarily included in a general solidarity scheme, GCS, as opposed to being an outsider to it, PCS, affects voluntary contributions of the super-rich and the non-rich (in and outside the VCM). Before we turn to our experimental exploration a few remarks on related literature may be helpful and, in any event, appropriate.

Certain collective or public good experiments share certain aspects of our PCS and GCS conditions. Since Isaac and Walker (1988), wealth asymmetry via heterogeneous endowments has been frequently explored experimentally (Kachelmeier and Shehata 1997; Chan et al. 1996; Cason and Khan 1999; Buckley and Croson 2006) what allows to test for equal endowment shares of voluntary contributions. ${ }^{1}$ The crowding out of charitable donations is explored by Blanco et al. 2012 (see also Bekkers and Wiepking 2011; Wiepking and Bekkers 2012 for surveys). So far there has been no focus on retrieving costly information beforehand. Like in GCS, where we allow the super-rich to participate in collective good provision and to donate. Some experiments let participants not only contribute but also reward (or sanction) others (Fehr and Gächter 2000; 2002; Andreoni et al. 2003; Masclet et al. 2003;

\footnotetext{
1 There exist other forms of asymmetry in linear public good experiments (Smith 2011; Kölle 2015; Chowdhury and Jeon 2014; Cason and Khan 1999).
} 
Sefton et al. 2007; Sutter et al. 2010). In our setup, charitable donations can be used to self-servingly influence collective good contributions of the non-wealthy.

In experimental research, generosity is typically operationalized as dictatorial reward allocation, as studied early in social psychology (Mikula 1972; Shapiro 1975) and later via impunity and dictator games (List 2007). In both our conditions the single super-rich is an allocator confronting several recipients, what renders both conditions rather unusual (see Engel 2011, for a meta study). Due to the nearly exclusive focus on dyadic interaction (Forsythe et al. 1994; Eckel and Grossman 1996; Engelmann and Strobel 2004) dictatorial reward allocation experiments with more than one recipient are not very common (Bolton et al. 1998; Selten and Ockenfels 1998; Engelmann and Strobel 2004, 2007).

In both PCS and GCS different fairness norms can apply. In the absence of a contribution norm and without punishment, low contributions have to be expected (Reuben and Riedl 2013). ${ }^{2}$ The less discriminatory GCS should trigger stronger solidarity concerns and render it, on average, the better institutional condition without inducing a contribution norm (Keser et al. 2017). One may also compare $R$-individuals with privileged groups (Reuben and Riedl 2009) with no freeriding incentive in their donating activities outside VCM.

Section 2 describes the experimental protocols in more detail. Section 3 reports the main results, separately for voluntarily contributing in PCS and GCS and similarly for voluntary donations by $R$-participants whose choice tasks depend more crucially on the institution. Finally, the payoffs in case of PCS and GCS are compared before concluding in Sect. 4.

\section{Experimental Protocols}

Partial Compulsory Solidarity, PCS, excludes the super-rich, $R$, from the solidarity group. $R$ is neither obliged to participate in the VCM nor entitled to an equal share of its benefits. General Compulsory Solidarity, GCS, differs from PCS by including $R$ in the group interaction under the VCM.

Under both, PCS and GCS conditions, $R$ has the option to improve the situation of specific other actors through "donations" to others. To target donations $R$ can, at a private cost to her, retrieve information about individual contributions of others under the VCM. (PCS and GCS are not alternative treatments in the technical sense. In particular, including $R$ in GCS increases the number of contributors without adjusting individual freeriding incentives).

An experimental society includes six members, one $R$, three $P$, and two $M$. The $M$ - are less well-off than $R$ - but better-off than $P$-types. The class specific individual initial endowments for $R, M, P$ are, respectively, $\rho=560, \mu=60$ and $\pi=20 \mathrm{ECU}$ (Experimental Currency Unit with $100 \mathrm{ECU}=€ 8$ ). This yields a total endowment of $560+2 \cdot 60+3 \cdot 20=740$; that is, nearly $75 \%$ of wealth is allocated to $R$. In the

\footnotetext{
2 Field observations confirm that participation to social activities in local communities is significantly lower the more heterogeneous the community is Alesina and La Ferrara (2000).
} 
following we also refer to super-rich $R$ as "wealthy" and to all $M$ and $P$ as "nonwealthy". The instructions refer to three different types as $P$ - $M$ - and $R$ - type.

As indicated already we refer to PCS and GCS not as treatments but as institutional conditions of an exploratory exercise in comparative institutional analysis of PCS and GCS (Plott 1997; Roth and Sotomayor 1992). In PCS, but not in GCS, $R$ can voluntarily contribute to the collective good from which in PCS only the non-wealthy, and, in GCS, all benefit equally. The non-negative integer contributions $c_{p i}, c_{m j}$ and $c_{r}$ for $i=1,2,3$ and $j=1,2$, may not exceed $20 \mathrm{ECU}$, corresponding to the wealth constraint $\pi=20$ of the poor. $M$-types can contribute only up to one-third of their endowment. In GCS, $R$ is also subject to this constraint on voluntary donations in the VCM and thus can donate only up to $1 / 28$ of $\rho=560$. Payoffs of the linear collective good games of five, PCS, respectively six, GCS, contributors assume the same MPCR of 0.4.

Even when $R$ is not engaged in collective good provision, $R$ - as all others - is informed about its rules and about the total contribution $C=c_{m 1}+c_{m 2}+c_{p 1}+c_{p 2}+c_{p 3}$ in PCS and $C+c_{r}$ in GCS. Before possibly donating, $R$ can purchase information concerning individual contributions, $c_{p 1}, c_{p 2}, c_{p 3}, c_{m 1}$ and $c_{m 2}$ at a cost for each information retrieval (mirroring that in the field information search is in general costly). After receiving the information she has paid for, $R$ decides on how much of the remaining endowment (560 minus the sum of information costs) she will donate to $M_{1}, M_{2}$, as well as to $P_{1}, P_{2}$ and $P_{3}$.

\subsection{Stages of the Decision Process}

The Decision Process Involves the Following Stages: First, in PCS the non-wealthy (in GCS) determine their contribution level; yielding the total contributions $C=c_{p 1}+c_{p 2}+c_{p 3}+c_{m 1}+c_{m 2}$ and $C+c_{r}$ in PCS and in GCS, respectively.

Second, the collective good level $C$, respectively $C+c_{r}$, becomes commonly known and the non-wealthy learn about their payoff ("wealth") before possible donations by $R$ :

- $\pi-c_{p i}+0.4 C$ for $P$-types in PCS; $\pi-c_{p i}+0.4\left(C+c_{r}\right)$ for $P$-types in GCS,

- $\mu-c_{m j}+0.4 C$ for $M$-types in PCS; $\mu-c_{m j}+0.4\left(C+c_{r}\right)$ for $M$-types in GCS,

- $\rho$ in PCS; $\rho-c_{r}+0.4\left(C+c_{r}\right)$ in GCS.

Third, $R$ can buy information about individual contributions at a cost of $e=10 E C U$ each. Depending on the (costly) information $R$ finally decides on how much of $560-n \cdot e$ (with $n \in \mathbb{N}$, denoting the number of information retrievals) to donate to $P$ - and $M$-types.

After factoring in $R$ 's voluntary targeted donations $d_{p i}$ and $d_{m j}$ for $i=1,2,3$ and $j=1,2$ overall earnings are:

- $\pi-c_{p i}+0.4 C+d_{p i}$ for $P$-types in PCS;

- $\pi-c_{p i}+0.4\left(C+c_{r}\right)+d_{p i}$ for $P$-types in GCS,

- $\mu-c_{m j}+0.4 C+d_{m j}$ for $M$-types in PCS; 
- $\mu-c_{m j}+0.4\left(C+c_{r}\right)+d_{m j}$ for $M$-types in GCS;

- $\rho-\sum_{i=1}^{3} d_{p i}-\sum_{j=1}^{2} d_{m j}-n \cdot e$ for $R$ in PCS;

- $\rho-\sum_{i=1}^{3} d_{p i}-\sum_{j=1}^{2} d_{m j}-n \cdot e-c_{r}+0.4\left(C+c_{r}\right)$ for $R$ in PCS;

In the experiment all participants play 24 periods in two phases of 12 periods each. For the first phase six participants are randomly chosen to interact with the same partners for twelve periods (partner design). After the first phase again six participants are randomly chosen to interact again with the same partners for 12 periods (again partner design). Across phases the assignment of specific participants to roles $R, M$, or $P$ remains invariant. Both phases are always played according to either PCS or GCS rules.

Of course, such repeated interaction in identical groups allows for both reaction to feedback information about past outcomes and anticipation of future effects. For instance, non-wealthy participants may hope that $R$ will reward contributions via donations in PCS and possibly also by contributing more in GCS. When retrieving information repeatedly, wealthy $R$ can identify other group members as $P_{i}$ or $M_{j}$. So, for instance, $R$ could verify whether a specific $P_{i}$ or $M_{j}$ increases his voluntary contribution after receiving a substantial donation via purchasing the relevant information.

After having described how the two institutional alternatives, PCS and GCS, are formally defined and experimentally implemented we can compare the two institutional settings PCS and GCS, in particular, with respect to the role of $R$. In PCS the super-rich participant $R$ can influence the payoffs only by redistributive donations allocated outside the VCM. In GCS both voluntary contributions and redistributive donations are viable for $R$. A donation costs $R$ one additional unit and provides one unit for one of the five others (should $R$ choose to donate to him). In PCS the marginal rate by which $R$ 's sacrifice of substantive self-interest transforms into benefit for (any) "other" is 1 . $R$ 's contribution of one unit in GCS generates 0.4 units to each of the six members of the solidarity group or in all $6 \times 0.4=2.4$. That is 0.4 units to $R$ and $5 \times 0.4=2$ for the five others at a "net" cost of $1-0.4=0.6$ to self. The transformation rate of the compulsory donation amounts to $2 / 0.6=10 / 3$. This transformation rate of contributions into collective benefits is more than three times larger than the one for the individualized voluntary donations. To put this slightly differently, by fully contributing, $c_{r}=20, R$ could provide $5 \times(0.4 \times 20)=40$ for the five others at a cost of 12 to self while $R$ would have had to sacrifice $5 \times 8=40$ units to generate an identical positive effect on each of the other members of the community by her voluntary targeted donations outside the VCM.

Compulsory solidarity as construed here is much more effective than voluntary solidarity. Yet it is also non-discriminatory. Voluntary donations can discriminate between the members of the lower endowment classes $P$ and $M$. Thereby $R$ can redistribute in a "retributive" manner and thereby express retributive emotions that are generally essential for the workings of moral and legal institutions (Mackie 1982). She can engage in acts of targeted altruistic reward in both the PCS and the GCS setting (as opposed to acts of altruistic punishment that could only be construed as withholding gifts). In GCS as opposed to PCS super-rich $R$ is obliged to 
participate in VCM. She willy-nilly participates in its benefits whether she voluntarily contributes in VCM or not. If she is concerned about fairly contributing to VCM she herself has to contribute to non-discriminatory solidarity. Her voluntary contributions to VCM may, however, implicitly reward non-deserving others. Targeted donations are more suitable to incentivize contributing behavior of the five others. Relying on a comparatively less effective process of transforming costs to self- including the necessary costly information retrieval- into benefits for others indicates a comparatively strong preference of $R$ for retributive, targeted over nondiscriminatory altruism. This part of the experimental exploration of alternative institutional rules clearly speaks to the standard conjecture that the decline of contributions in standard VCM's is in the first place due to other-regarding resentment against free-riding and not so much a consequence of self-regarding motives to freeride (normally rather naively discredited as greed).

Final payments are based on one randomly selected period of one randomly selected phase. We ran 13 sessions at CESARE laboratory of University Luiss with 288 students, recruited using Orsee (Greiner 2015) (11 sessions with 24 subjects and 2 sessions with 12 subjects each); 192 subjects participated in PCS and 96 in GCS. Except for the possibility to voluntarily donate, GCS is a rather usual collective good design. Compared to this, PCS additionally deviates by excluding $R$-members from collective good provision and deviates more fundamentally from usual collective good designs. It is because of this that we collected more PCS data. Subjects were provided with a hard copy of the instructions, which were read aloud by the experimental proctor (for an English translation of the instructions see Sect. 5.1). The experiment was fully computerized using z-Tree (Fischbacher 2007). Overall, subjects spent about $80 \mathrm{~min}$ in the laboratory, and earned on average $€ 14.30$. The altogether 24 participants of each session were restricted to two half groups and randomly re-matched after the first phase within the same half group: participants were not informed about this restricted re-matching.

\section{Results}

After analyzing contributions both in PCS and GCS, we discuss the information requests and donations by $R$, by distinguishing and comparing "blind" (in the sense of no information retrievals) and "non-blind" donors among $R$-participants, before addressing welfare implications.

\subsection{Contribution Behavior}

The average contribution dynamics in Fig. 1 for $P, M$ and, in GCS, also $R$ are consistent with the usual decline observed in repeated collective good experiments. When $R$ is included, average contributions of $P$-participants (4.25 in PCS vs. 6.19 in 


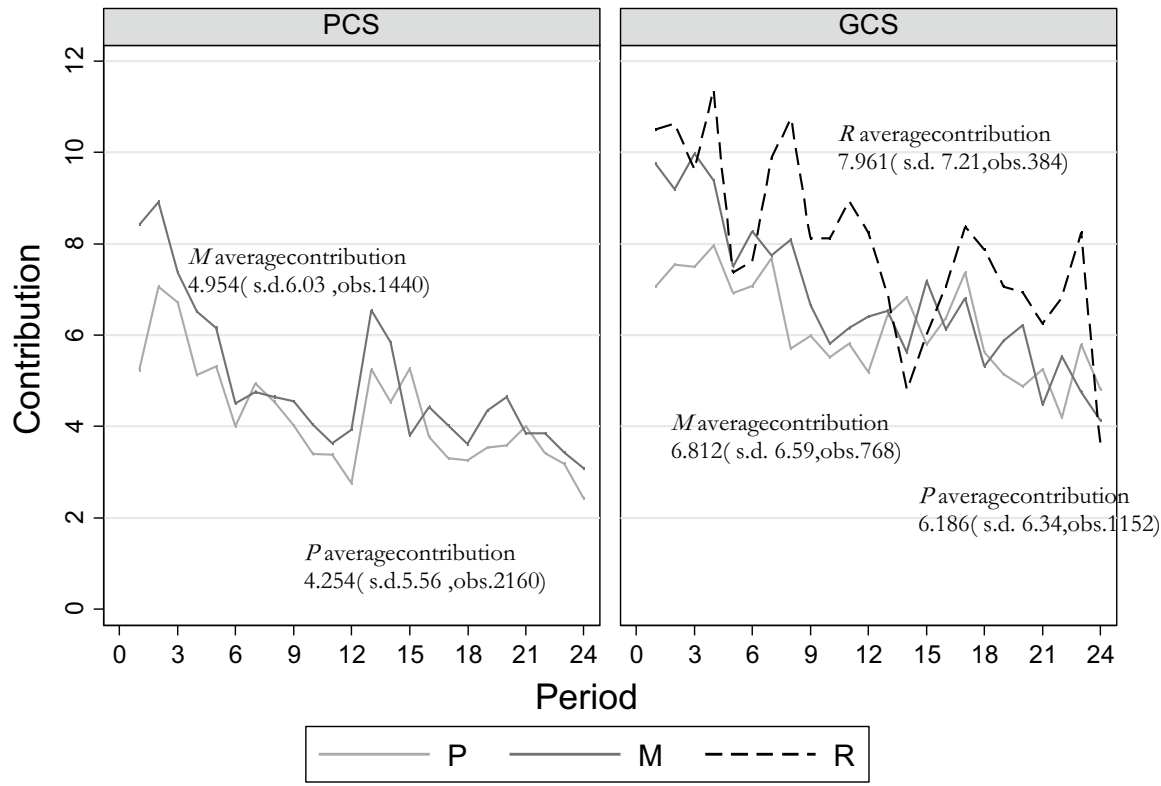

Fig. 1 Contributions by condition and role

GCS) and $M$-participants (4.95 in PCS vs. 6.81 in GCS) are significantly higher (p values are computed using a bootstrapped $t$ test on group averages (GA) as the unit of observation with 1000 bootstrapped samples $^{3}$; GA p value $<0.001$ ).

Result 1 Compared to PCS the average contributions of $P$-and $M$-participants in GCS are significantly higher.

There are two main explanations ${ }^{4}$ :

1. the increased efficiency of individual contributions due to including $R$ in GCS discourages freeriding,

2. the procedural fairness of GCS crowds in and strengthens solidarity concerns.

In PCS the average $M$-contribution significantly exceeds the $P$-contribution (4.95 vs. 4.25 , respectively with GA p value $<0.001)$. In GCS this difference is also significant and positive (6.81 for $M$ vs. 6.19 for $P$, GA p value=0.016). Thus, there

\footnotetext{
3 To avoid assumptions on the normality of data, all tests are run using the bootstrapped $t$ test method with 1000 bootstrap samples. Where possible, the tests also are run on group averages (GA) as the unit of observation (Moffatt 2015).

4 This confounding could be avoided by a richer design with intermediate conditions between PCS and GCS, for example one letting $R$ gain from contributions in PCS but not contribute, and one letting $R$ contribute but not gain from contributions in GCS. Here we are interested in the likely effects of an institutional reform and not in treatment effects, based on comparison of PCS and GCS with intermediate conditions.
} 




Fig. 2 Contribution by donation received in previous period

is solidarity across endowment classes even in PCS. $R$-participants contribute significantly more than the others $(7.96$, with GA p values $\leq 0.001$ compared to both, $P$ and $M$ ).

Result $2 M$-members contribute significantly more than $P$-members in both PCS and GCS. Furthermore, $R$-participants, in GCS, contribute significantly more than both $P$ - and $M$-members.

To answer whether contributions of $P$ and $M$ are boosted by donations and (in GCS by) contributions of $R$, we distinguish no and positive donations and plot individual contributions after (not) having received a donation in the previous period. Figure 2 clearly reveals that $P$ beneficiaries contribute more, both in PCS and GCS (see top section of Table 1). The result is significant for $P$ in both conditions (p values $<0.001$ both in PCS and GCS). ${ }^{5}$ Positive donations seem to have a positive (and significant) effect on $M$ contributions as well (see $M$ section of Table 1). Furthermore, contributions of $P$ and $M$ beneficiaries are significantly different; $M$-types are more cooperative which does not hold when comparing the contributions of $P$ and $M$ without prior donation (see bottom section of Table 1).

Although non- $R$-participants are unaware whether being observed by $R$ over time, $P$ - and $M$-participants may infer this monitoring from changing donations. Figure 3 displays the dynamics of $P$ - and $M$-contributions across time in case of uninformed

\footnotetext{
5 The p-values, in this case, do not refer to group level analysis due to the specific individual effect of donations.
} 
Table 1 Pairwise test on contribution by donation received in previous period

\begin{tabular}{|c|c|c|c|c|c|c|c|c|}
\hline & & \multicolumn{3}{|l|}{ PCS } & \multicolumn{3}{|l|}{ GCS } & \multirow[t]{2}{*}{$\mathrm{p}$ value } \\
\hline & & Obs & Mean & Std. Dev. & Obs & Mean & Std. Dev. & \\
\hline \multicolumn{9}{|c|}{$P$ average contribution } \\
\hline \multicolumn{2}{|l|}{ Non-beneficiary } & 1394 & 3.846 & 5.44 & 594 & 4.860 & 5.58 & 0.000 \\
\hline \multicolumn{2}{|l|}{ Beneficiary } & 586 & 4.918 & 5.76 & 462 & 7.773 & 6.89 & 0.000 \\
\hline \multicolumn{2}{|l|}{$\mathrm{p}$ value } & & 0.000 & & & 0.000 & & \\
\hline \multirow[t]{2}{*}{ Benefitting from } & Informed $R$ & 335 & 5.896 & 6.07 & 175 & 8.886 & 6.86 & 0.000 \\
\hline & Blind $R$ & 251 & 3.614 & 5.03 & 287 & 7.094 & 6.84 & 0.000 \\
\hline \multicolumn{2}{|l|}{$\mathrm{p}$ value } & & 0.000 & & & 0.005 & & \\
\hline \multicolumn{9}{|c|}{$M$ average contribution } \\
\hline \multicolumn{2}{|l|}{ Non-beneficiary } & 936 & 3.942 & 5.51 & 416 & 5.481 & 6.20 & 0.000 \\
\hline \multicolumn{2}{|l|}{ Beneficiary } & 384 & 6.630 & 6.42 & 288 & 8.441 & 6.57 & 0.000 \\
\hline \multicolumn{2}{|l|}{$\mathrm{p}$ value } & & 0.000 & & & 0.000 & & \\
\hline \multirow[t]{2}{*}{ Benefitting from } & Informed $R$ & 221 & 7.647 & 6.60 & 113 & 9.664 & 5.96 & 0.004 \\
\hline & Blind $R$ & 163 & 5.252 & 5.91 & 175 & 7.651 & 6.84 & 0.001 \\
\hline \multicolumn{2}{|l|}{$\mathrm{p}$ value } & & 0.000 & & & 0.012 & & \\
\hline \multirow{2}{*}{\multicolumn{2}{|c|}{$\mathrm{p}$ value $P$ vs. $M$ beneficiary }} & & & & & & PCS & 0.000 \\
\hline & & & & & & & GCS & 0.034 \\
\hline \multirow{2}{*}{\multicolumn{2}{|c|}{$\mathrm{p}$ value $P$ vs. $M$ non-beneficiary }} & & & & & & PCS & 0.185 \\
\hline & & & & & & & GCS & 0.102 \\
\hline
\end{tabular}

We report the $\mathrm{p}$ values $t$ test on individual observations bootstrapped with replications on the order of 1000. "Informed" defines those $R$-participants retrieving at least one information related to one member of the group, i.e., we include in the group "Benefitting from informed $R$ " all members of the group where $\mathrm{R}$ has bought one/some/all information in the period before

vs. (more or less) informed $R$-participants, separately for PCS (left chart) and GCS (right chart) ${ }^{6}: P$ and $M$ contributions are lower when $R$ donates blindly than after investing in information in $t-1$ (see bottom section of Table 1). The non-wealthy seem aware of $R$ conditioning donations based on monitoring their individual contributions.

Result 3 Voluntary donations of informed $R$-participants boost voluntary cooperation of the non-wealthy

Result 3 suggests that some non-wealthy view $R$-donations as a bonus system according to which $R$ monitors individual contributions and conditions donations on individual contributions. Table 2 validates that $P$ and $M$ contributions are positively correlated to past contribution sum and the received donation. ${ }^{7}$ Note also that

\footnotetext{
6 "Informed" defines those $R$-participants retrieving at least one information related to one member of the group, i.e., we include in the group "benefitting from informed $R$ " all members of the group where $R$ has bought one/some/all information in the period before.

7 We provide some robustness check for the tobit estimation; in Sect. 5.2, Table 7 shows the multilevel estimations to highlight the possible effect of heterogeneity. The Likelihood-ratio test accepts the null hypothesis for all specifications; we do not have between-session or between-group variation.
} 

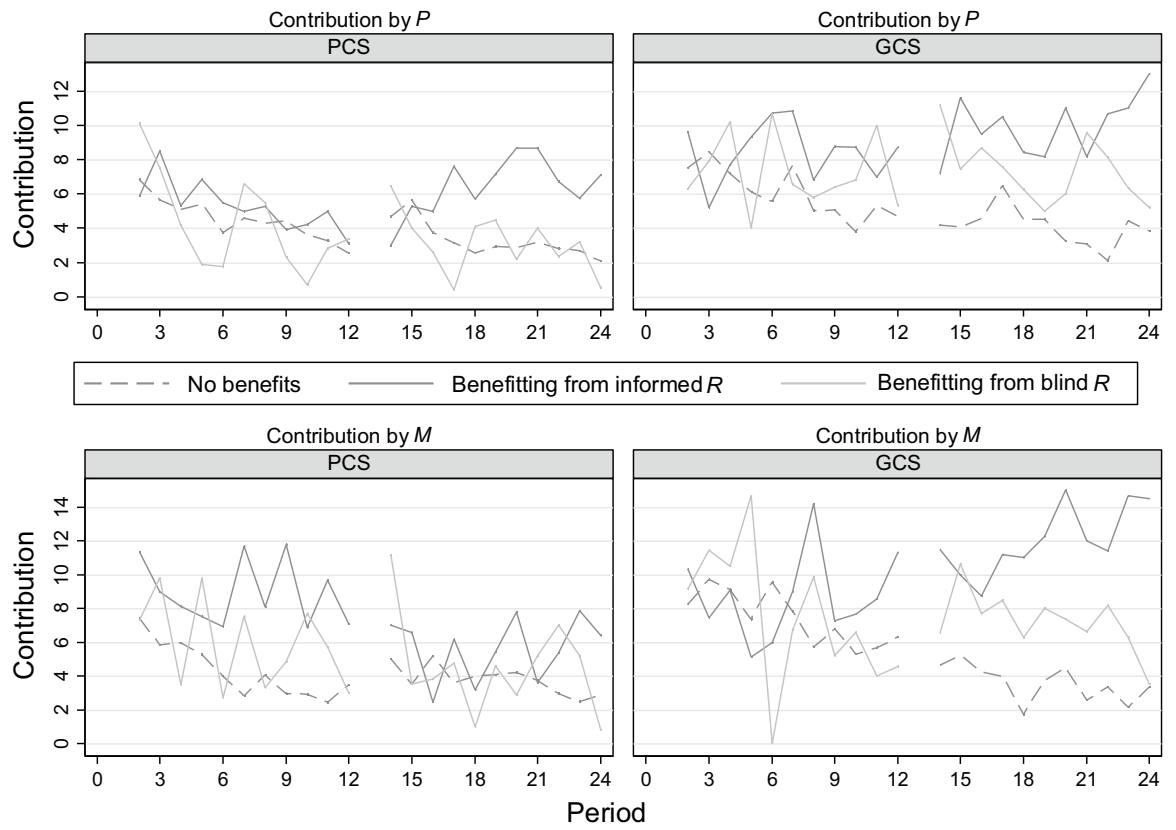

Fig. $3 P$ and $M$ contributions by blind and non-blind $R$

Table 2 Random-effects tobit model regression on $P$ and $M$ contributions

\begin{tabular}{|c|c|c|c|c|}
\hline \multirow[t]{2}{*}{ Dependent variable } & \multicolumn{2}{|c|}{$P$-contribution (1) } & \multicolumn{2}{|c|}{$M$-contribution (2) } \\
\hline & $\beta$ & S.e. & $\beta$ & S.e. \\
\hline Treatment: GCS & $1.823^{*}$ & $(1.06)$ & 0.987 & $(1.30)$ \\
\hline Sum contribution $(\mathrm{t}-1)$ & $0.088 * * *$ & $(0.01)$ & $0.110^{* * *}$ & $(0.01)$ \\
\hline Donation received $(\mathrm{t}-1)$ & $0.247 * * *$ & $(0.05)$ & 0.071 & $(0.06)$ \\
\hline Uninformed $R(\mathrm{t}-1)$ & -0.149 & $(0.44)$ & $-1.111^{* *}$ & $(0.56)$ \\
\hline $\begin{array}{l}\text { Donation received } \\
(\mathrm{t}-1) \times \text { Uninformed } \\
R(\mathrm{t}-1)\end{array}$ & $-0.211^{* * *}$ & $(0.06)$ & -0.031 & $(0.07)$ \\
\hline Female & -0.068 & $(1.00)$ & $3.330 * * *$ & (1.23) \\
\hline Phase & $-1.020 * * *$ & $(0.26)$ & $-1.754 * * *$ & $(0.34)$ \\
\hline Period & $-0.323 * * *$ & $(0.04)$ & $-0.348 * * *$ & $(0.06)$ \\
\hline Constant & 1.469 & $(1.70)$ & 2.913 & $(2.02)$ \\
\hline $\mathrm{N}$ & 3036 & & 2024 & \\
\hline
\end{tabular}

Standard errors in parentheses: $* * * \mathrm{p}<0.01, * * \mathrm{p}<0.05, * \mathrm{p}<0.1$

$P$ contributions react more strongly to donations by (partially) informed donors (see the negative and significant interaction term in Table $2^{8}$ ).

\footnotetext{
8 When separating the analysis by conditions, we find that the interaction result holds only for PCS.
} 
Table $3 R$-individuals' average total donations to $P$ only, and $M$ only

\begin{tabular}{|c|c|c|c|c|c|}
\hline & \multicolumn{2}{|c|}{ PCS (720 obs.) } & \multicolumn{2}{|c|}{ GCS (384 obs.) } & \multirow[t]{2}{*}{$\mathrm{p}$ value } \\
\hline & Mean & Std. Dev. & Mean & Std. Dev. & \\
\hline \multicolumn{6}{|l|}{ Donation } \\
\hline Phase 1 and Phase 2 & 9.810 & 28.29 & 9.549 & 12.59 & 0.837 \\
\hline Phase 1 & 11.486 & 35.10 & 10.625 & 13.83 & 0.701 \\
\hline Phase 2 & 8.133 & 19.12 & 8.474 & 11.15 & 0.802 \\
\hline $\mathrm{p}$ values & 0.048 & & 0.087 & & \\
\hline \multicolumn{6}{|l|}{ Donation to $P$} \\
\hline Phase 1 and Phase 2 & 5.663 & 16.79 & 5.719 & 8.48 & 0.944 \\
\hline Phase 1 & 6.514 & 20.63 & 6.630 & 9.72 & 0.938 \\
\hline Phase 2 & 4.811 & 11.73 & 4.807 & 6.93 & 0.000 \\
\hline $\mathrm{p}$ values & 0.113 & & 0.024 & & \\
\hline \multicolumn{6}{|l|}{ Donation to $M$} \\
\hline Phase 1 and Phase 2 & 4.147 & 12.80 & 3.831 & 5.75 & 0.572 \\
\hline Phase 1 & 4.972 & 14.94 & 3.995 & 6.04 & 0.249 \\
\hline Phase 2 & 3.322 & 10.17 & 3.667 & 5.45 & 0.653 \\
\hline $\mathrm{p}$ values & 0.064 & & 0.570 & & \\
\hline
\end{tabular}

We report the $\mathrm{p}$ values of $t$ tests on individual observations bootstrapped with replications on the order of 1000

\subsection{Behavior of Wealthy Participants}

$R$-type participants donate on average less than 10 ECU in total (Table 3). While redistributive $R$ - donations start off significantly higher in PCS, they significantly drop below those in GCS in the second phase. ${ }^{9}$

The decrease from phase 1 to phase 2 of $R$-donations applies across conditions while being weakly significant in GCS (see the p values of bootstrapped $t$ tests in Table 3 ). Even though $R$ in GCS can more efficiently display solidarity via contributing rather than donating, this does not crowd out voluntary donations. Actually, $R$-participants in GCS donate as much as in PCS (p value $=0.837$ ): $R$-participants in GCS (PCS) donate 57.6 (39.6) percent of the time when measured as the ratio of positive donation sums of each $R$ in each of the 24 periods in which she could donate. This implies that average donations in GCS are smaller (Table 3). This seems to suggest that at least partly $R$-donations have been substituted by more efficient voluntary $R$-contributions in GCS. But do $R$-participants either donate or contribute? The answer is no: $R$-participants, who donate, contribute on average 10.27 whereas those not donating contribute only 4.83 ( $t$ test $^{10} \mathrm{p}$ value $\left.<0.001\right)$.

\footnotetext{
${ }^{9}$ Figure 12 (in Sect. 5.2) displays some outliers, in particular one wealthy individual who donates most of her endowment, ID $=44$. We removed this wealthy participant and her group from the analysis (including all previous results in Sect. 3.1).

10 We perform a $t$ test on individual observations bootstrapped with replications on the order of 1000 .
} 
Table 4 Frequency of donor types

\begin{tabular}{llllll}
\hline Donor type & \multicolumn{2}{l}{ PCS } & & \multicolumn{2}{l}{ GCS } \\
\cline { 2 - 3 } \cline { 6 - 6 } \cline { 6 - 6 } & Frequency & $\%$ & & Frequency & $\%$ \\
\hline Non-donors & 28 & 46.67 & 9 & 28.13 \\
Small donors & 21 & 45.00 & 14 & 43.75 \\
Substantial donors & 11 & 18.33 & 9 & 28.13 \\
& 60 & 100 & 32 & 100 \\
\hline
\end{tabular}

Classification is based on the sum of the five donations per period. The categories represent the average donations in 12 periods of a phase. Non-Donors: <1 ECU; Small Donors: 1-15 ECU; High Donors: > 15 ECU



Fig. 4 Donation from blind and non-blind $R$

Table 4 distinguishes three categories of $R$-participants, based on the average donation in each phase: those donating virtually nothing, and those who, on average, donate only small, respectively more substantial amounts. The share of $R$-participants not donating is $46.67 \%$ in PCS and larger than $28.13 \%$ in GCS, whose share of "Substantial Donors" is larger than in PCS (28.13\% vs. 18.13\%). This suggests crowding in: $R$-participants more frequently donate in GCS than in PCS.

Figure 4 distinguishes average donations of $R$-participants with no and with some information retrieval (Fig. 13 in Sect. 5.2 excludes non-donors). The positive difference in information retrieval between conditions PCS and GCS in phase 1 is significant, $(\mathrm{p}$ value $=0.03$ ) with GCS being higher, see Fig. 5 . 


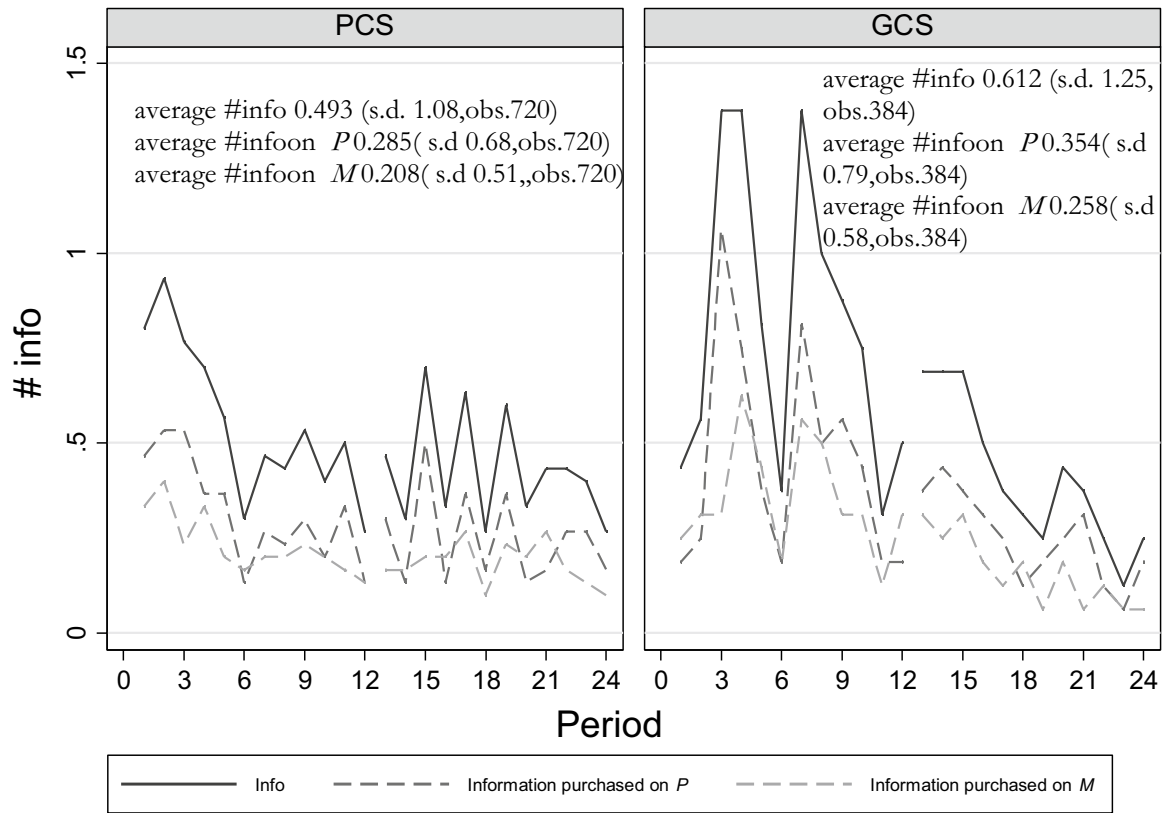

Fig. 5 Information purchased on $P$ and on $M$

In both conditions, average donations of $R$-participants with information (referred to as "info") exceed across time those of $R$-types without information (referred to as "blind") where the differences are strikingly large, see Fig. 4. Apparently (not) investing in information goes hand in hand with (not) donating: some $R$-participants keep their eyes closed while generous ones apparently want to learn how needy the non-wealthy are and how they could be encouraged similar to principals in principal-agent models.

Result 4 Information retrieval goes along with donating: the altogether 46 R-participants investing in information donate significantly more.

Figures 6 and 7 display how frequency shares of the different $R$ types evolve over time. Figure 6 categorizes $R$-participants into four types: (1) those who donate and purchase costly information, (2) those who donate but do so blindly, (3) those who purchase information without donating, and (4) those who neither purchase information nor donate. In PCS the percentage of $R$-participants with possibly minimal, positive donations starts off above $60 \%$. After the first half of the first phase the share of $R$-participants who donate drops by around $50 \% .^{11}$

For GCS, Fig. 7 distinguishes "blind" and "non-blind" donors, and further characterizes $R$-participants into four types: (1) those who both donate and contribute

\footnotetext{
11 Remember that one phase lasts 12 periods before groups are reshuffled whereas endowment types remain constant. Period 13 in Figs. 6 and 7 marks the start of a new phase after reshuffling, yet we find no restart effect.
} 


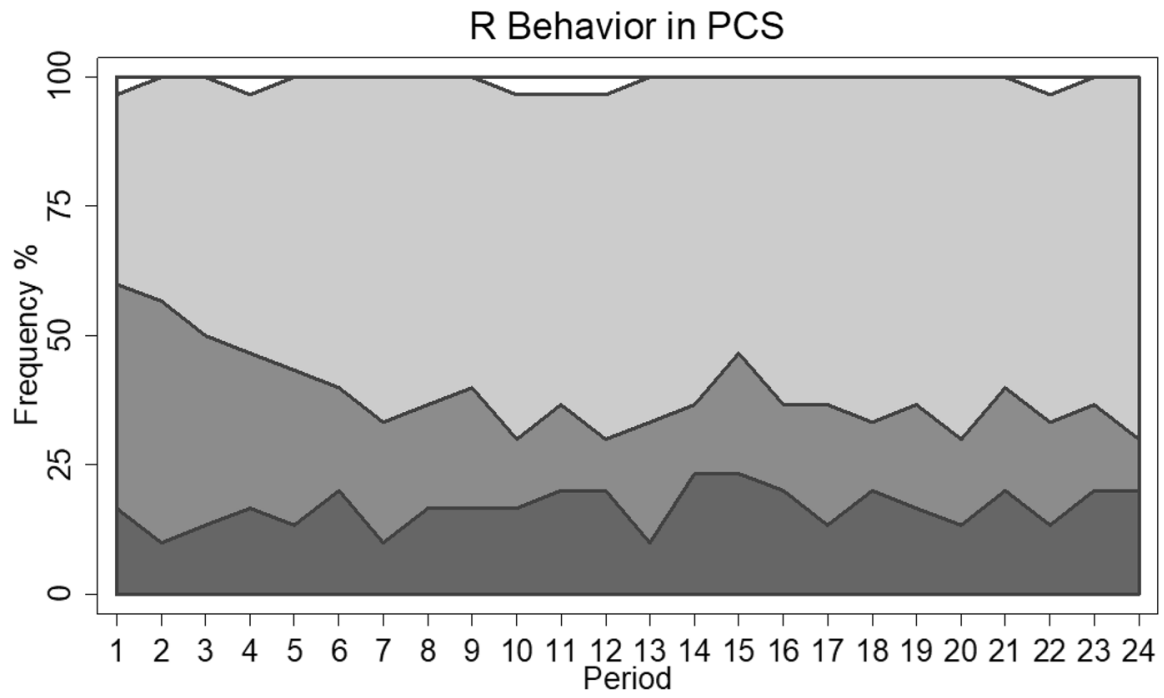

\begin{tabular}{lll|}
\hline & Blind Donation & Non-Blind Donation \\
\hline Blind No-Donation & $\square$ Non-Blind No-Donation
\end{tabular}

Fig. 6 Frequency of donating (>1 ECU) by $R$-participants (in PCS)
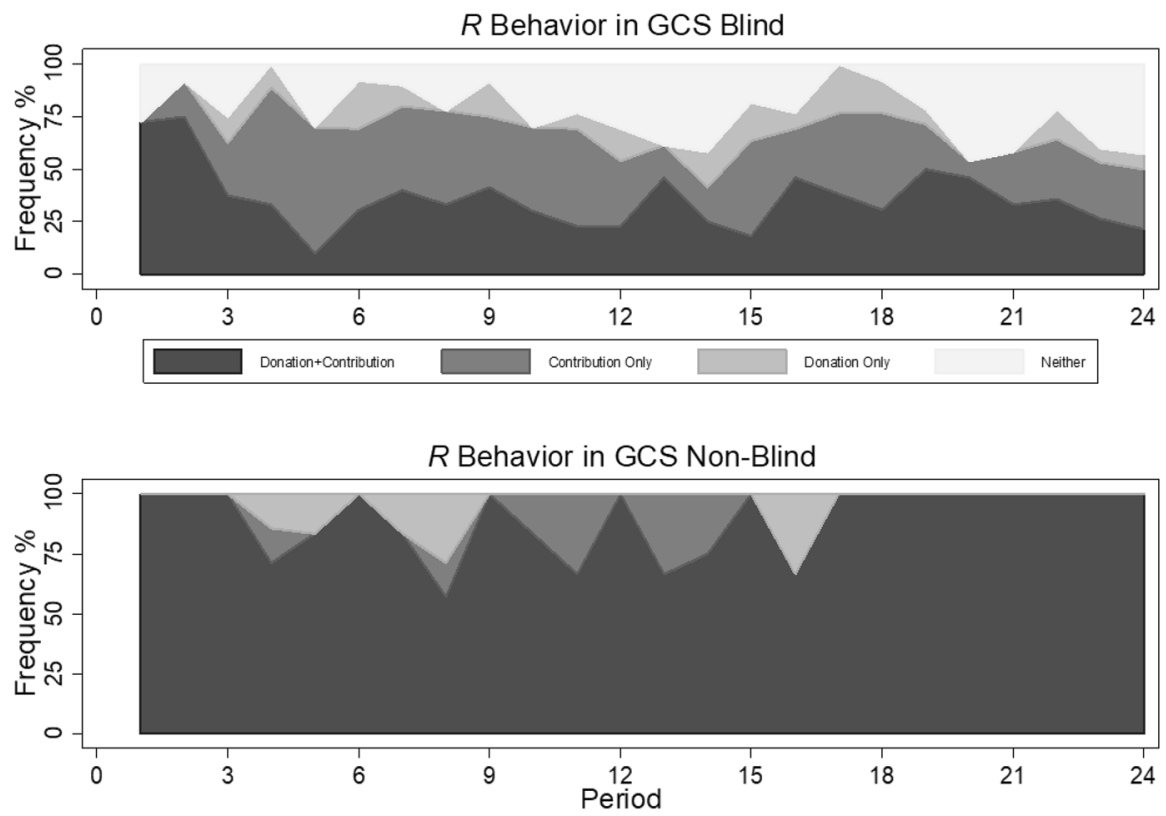

Fig. 7 Frequency of $R$-donation ( $>1 \mathrm{ECU}$ ) and contribution to the public good in GCS 
Table 5 Random-effects tobit model regression on $R$-donations

\begin{tabular}{lllll}
\hline & GCS (1) & Dependent: pool (2) & $R$-donation PCS (3) & GCS (4) \\
\hline Own contribution & $0.272 * *(0.12)$ & & & \\
Sum contribution & & $0.221 * * *(0.09)$ & $0.077(0.16)$ & $0.254 * * *(0.04)$ \\
Donation (t-1) & $0.435^{* * *}(0.07)$ & $0.477 * * *(0.04)$ & $0.478 * * *(0.06)$ & $0.336^{* * *}(0.07)$ \\
Information acquired & $0.337 * * *(0.06)$ & $0.088(0.11)$ & $-0.076(0.21)$ & $0.303 * * *(0.06)$ \\
Female & $-0.064(4.79)$ & $-0.489(9.71)$ & $1.898(17.84)$ & $-0.508(5.22)$ \\
Phase & $0.513(1.31)$ & $-2.619(2.33)$ & $-5.377(3.98)$ & $1.119(1.24)$ \\
Period & $-0.573 * * *(0.21)$ & $-0.912 * *(0.37)$ & $-1.371 * *(0.65)$ & $-0.364 *(0.20)$ \\
Condition & & $9.224(9.91)$ & & \\
Constant & $-1.833(3.97)$ & $-30.428 *(15.76)$ & $-22.075(15.10)$ & $-10.908 * *(4.39)$ \\
$\mathrm{N}$ & 352 & 1012 & 660 & 352 \\
\hline
\end{tabular}

Standard errors in parentheses: $* * * \mathrm{p}<0.01, * * \mathrm{p}<0.05, * \mathrm{p}<0.1$

Table 6 Random-effects tobit model regression on $R$-contributions

\begin{tabular}{lll}
\hline & \multicolumn{2}{l}{ Dependent: $R$-contribution in GCS } \\
\cline { 2 - 3 } & 1 & 2 \\
\hline Own contribution $(\mathrm{t}-1)$ & $0.179 * *(0.08)$ & \\
Sum contribution $(\mathrm{t}-1)$ & & $0.096^{* * *}(0.03)$ \\
Donation (t-1) & $0.292^{* * *}(0.05)$ & $0.256^{* * *}(0.06)$ \\
Information acquired (t-1) & $-0.045(0.05)$ & $-0.038(0.05)$ \\
Female & $4.094(2.88)$ & $4.066(2.82)$ \\
Phase & $-2.783^{* * *}(0.94)$ & $-2.366^{* *}(0.97)$ \\
Period & $-0.012(0.15)$ & $0.078(0.15)$ \\
Constant & $5.246^{* *}(2.62)$ & $1.841(3.04)$ \\
$\mathrm{N}$ & 352 & 352 \\
\hline
\end{tabular}

Standard errors in parentheses. We control the results also by estimating the GMM model using xtabond with one lag period (Arellano and Bond 1991). The results are consistent with the tobit model $* * * \mathrm{p}<0.01, * * \mathrm{p}<0.05, * \mathrm{p}<0.1$

to the PG, (2) those who only donate, (3) those who only contribute to the PG, (4) those who neither donate nor contribute. Most non-blind $R$-participants engage in both, donating and contributing: $90 \%$ of the $R$-participants who invest in information donate as well as contribute. In comparison, blind $R$-participants often only contribute although blind donations are higher in GCS than in PCS.

Result 5 In GCS most $R$-participants (90\%) reveal social concerns via costly information retrieval, voluntarily contributing and donating

Table 5 on $R$-donations in GCS (Model 1) rejects "crowding out" of charitable donations and confirms a positive effect of $R$ 's own contributions, past own donations and partly of contribution sums (Models 4 for GCS, Model 2 for pooled data) on R-donations. Information retrieval enhances voluntary cooperation of the nonwealthy in GCS but not in PCS. Only few $R$-participants, who are substantially 

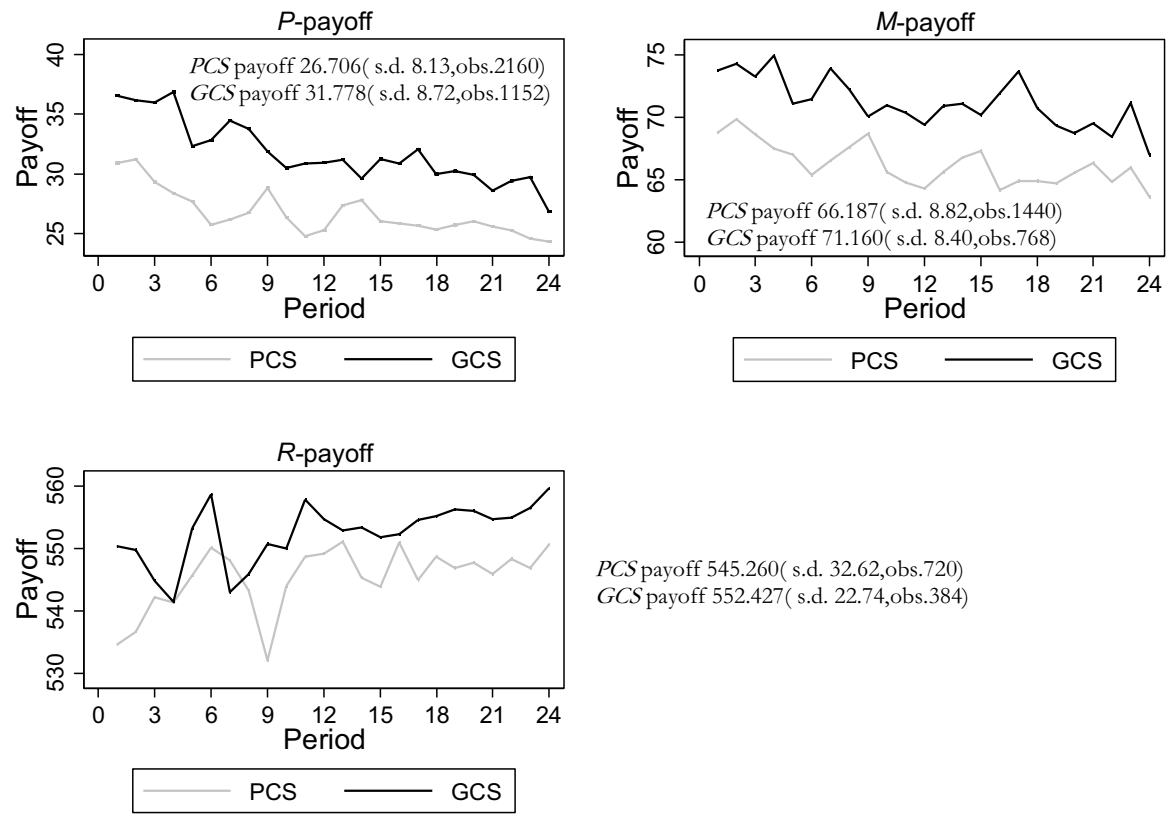

$P C S$ payoff 545.260 (s.d. 32.62 ,obs. 720$)$ $G C S$ payoff 552.427 (s.d. 22.74 ,obs.384)

Fig. 8 Payoff by role and condition. We perform a bootstrapped $t$ test (1000 replications) on the individual payoff by role checking for significant difference between condition PCS and GCS: for all pairwise comparisons (GCS vs. PCS) p values are $<0.001$

donating in PCS, monitor and reward higher contributions (Table 4) to inspire voluntary cooperation of the non-wealthy.

Table 6, using a random-effects tobit model, reveals how $R$-contributions in GCS are significantly related to own previous contributions (Model 1), past donations, as well as to past contribution sums (Model 2). This suggests that $R$-participants, who care for the non-wealthy, do not merely substitute donations by more efficient contributions but rather employ both to improve the wellbeing of their fellow group members and their society, especially when also retrieving information about individual contributions. ${ }^{12}$ Table 6 reveals lower $R$-contributions in the second phase but not across periods within a phase.

\subsection{Payoff Analysis}

Figure 8 compares the average payoffs for the three groups across time between GCS and PCS. Although average $P$-payoff (top-left graph in Fig. 8) is smoothly decreasing in both conditions, it is significantly higher in GCS than PCS. This holds also for $M$-participants (top-right graph in Fig. 8). Most strikingly, $R$-members are,

\footnotetext{
12 Due to high correlation between donations and information purchased, we find that the latter is significant only when we run the same model without donation covariate.
} 

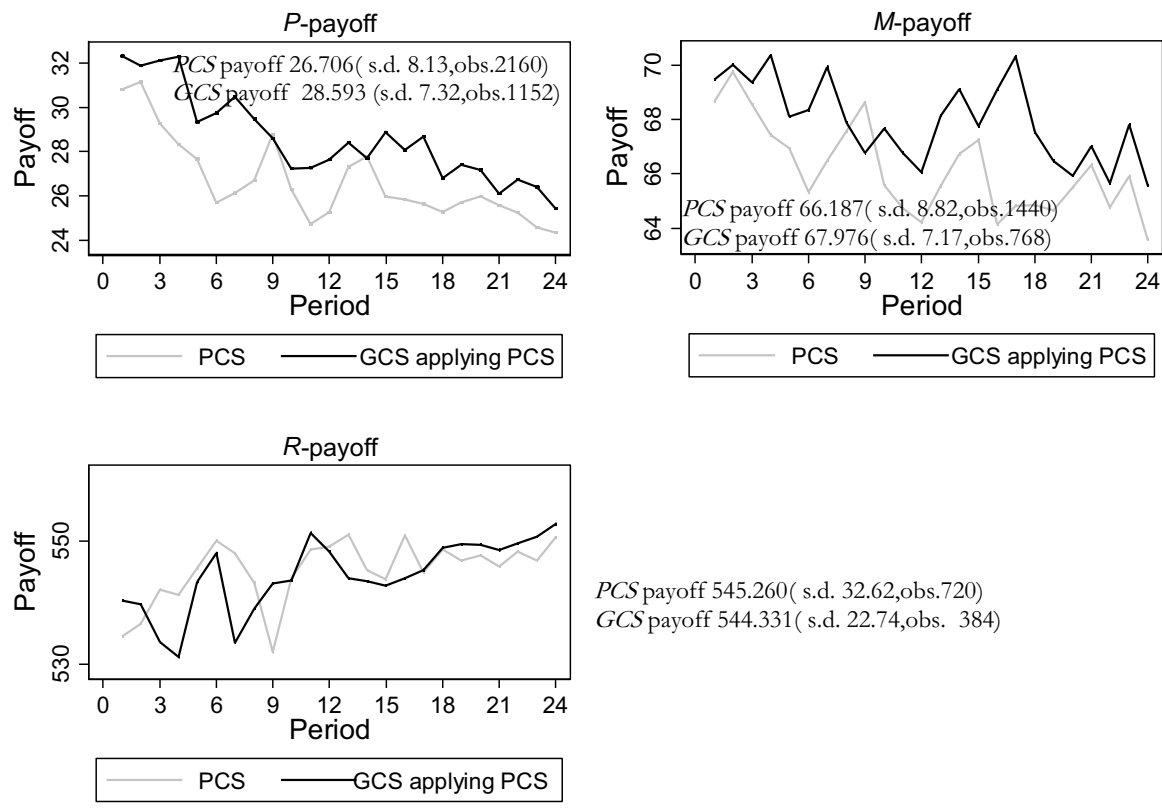

PCS payoff 545.260 (s.d. 32.62 ,obs. 720 )

GCS payoff 544.331( s.d. 22.74,obs. 384)

Fig. 9 Payoff by role and condition, when excluding R-member from public provision in GCS. We perform a bootstrapped $t$ test (1000 replications) on the individual payoff by role checking for significant difference between conditions PCS and GCS: for $P$ and $M$ pairwise comparisons (GCS vs. PCS) $p$ values are $<0.001$. The payoff for $R$ does not significantly differ across treatments ( $\mathrm{p}$ value $=0.602$ )

on average, also better off in GCS than in PCS. On average, no endowment type, $P$, $M$ and $R$, is worse off under GCS than under PCS institutional rules.

This may be partly due to the higher efficiency of collective good provision when $R$ is included. Let us therefore neglect $R$-contributions when comparing GCS with PCS and simulate efficiency without $R$-contributions. Figure 9 displays the average (simulated) payoffs across periods for $P$ - (top-left graph) and $M$-members (top-right graph) when excluding $R$-contributions. ${ }^{13}$

Even when $R$-contributions are excluded average $P$ - and $M$ - payoffs are significantly higher in (simulated) GCS than in PCS. The bottom graph in Fig. 9 reports simulated $R$-payoffs for GCS when neglecting their contribution costs and collective good benefits but including donations and information costs: the average payoff is significantly lower in GCS, partly due to the significantly higher information $\operatorname{costs}^{14}$ in GCS than in PCS (see Fig. 5).

Result 6 According to our testbed analysis in GCS all types are better off than in PCS.

\footnotetext{
${ }^{13}$ This implies that we simulate the efficiency level of GCS by excluding the direct effects of R-contributions but not of their indirect ones.

${ }^{14}$ Information costs in our setup lower efficiency, which is not necessarily the case in the field where they may also generate income and have re-distributional effects.
} 


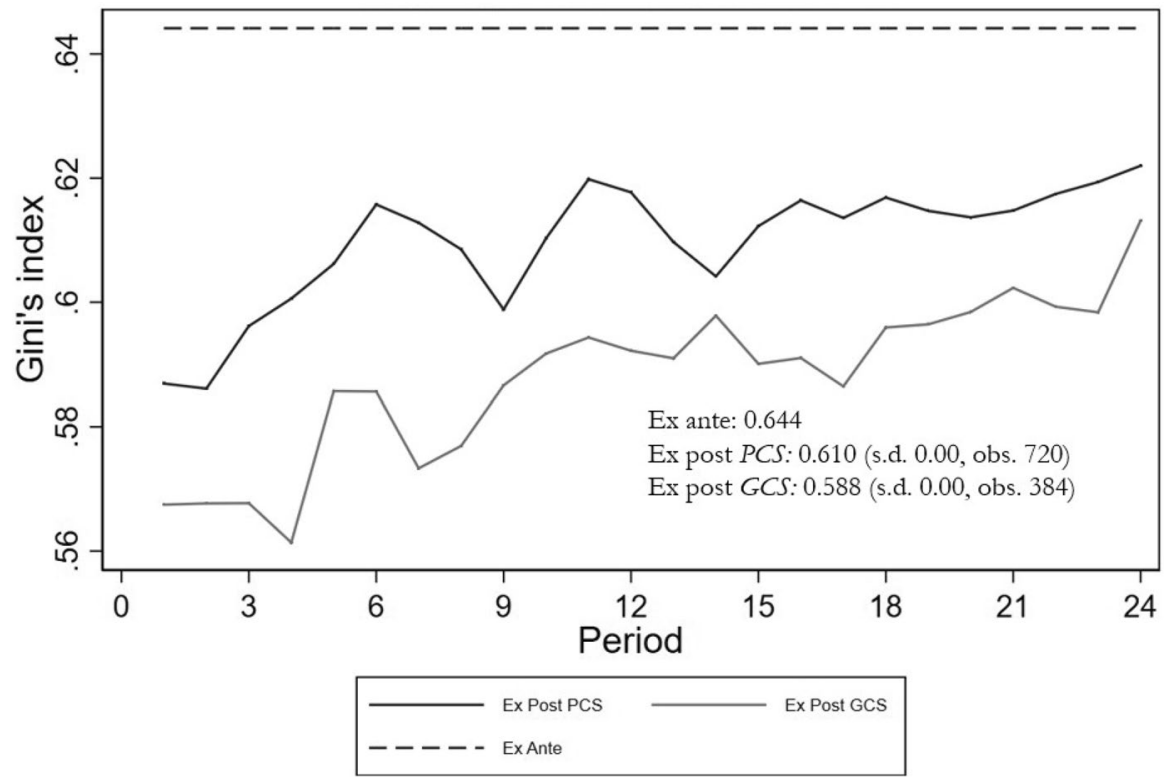

Fig. 10 Gini inequality index in PCS and GCS. We perform a bootstrapped $t$ test (1000 replications) on individual observations checking for significant difference between condition PCS and GCS: $p$ values $<0.001$

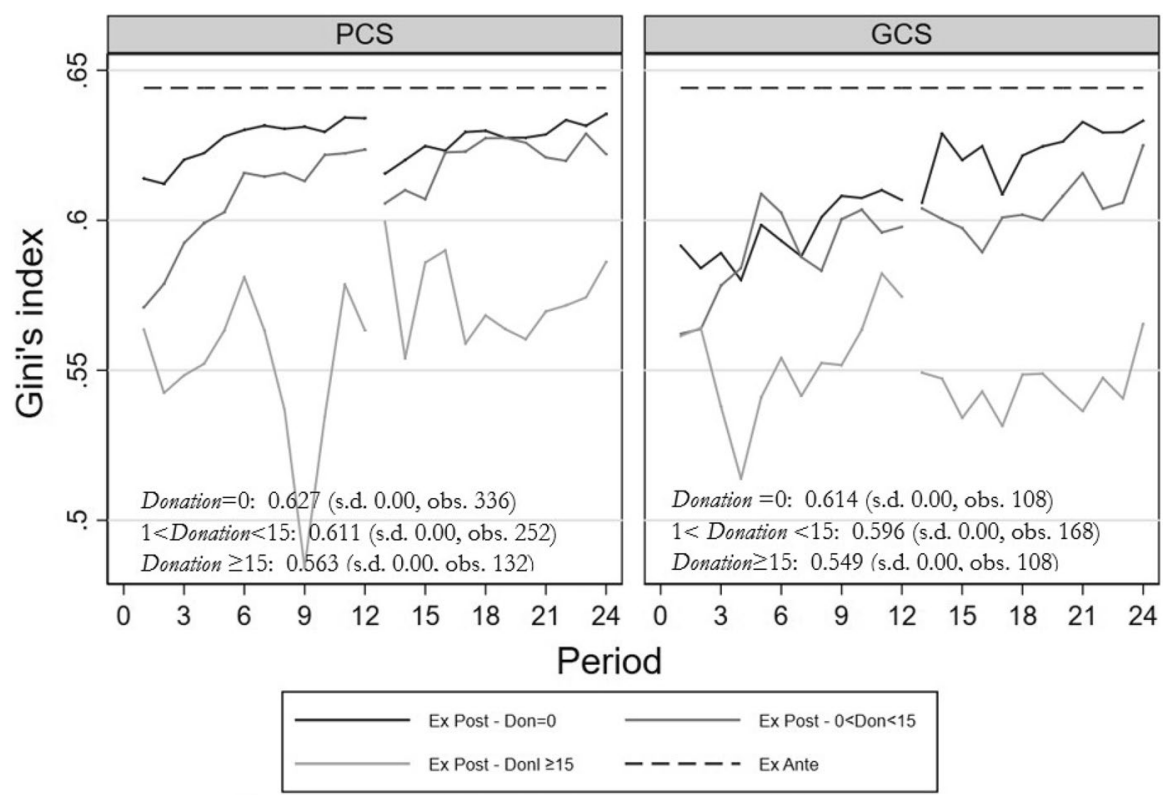

Fig. 11 Gini index by donor types. We perform a bootstrapped $t$ test (1000 replications) on individual observations (within treatment) checking for significant difference across donor types: $\mathrm{p}$ values $<0.001$ 
This result is supported by analyzing how dispersed the payoffs are. The Gini index ${ }^{15}$ compares the variation from the initial dispersion of endowments (identical in PCS and GCS) with the later inequality in periodic payoffs.

Figure 10 shows that the inequality level is significantly lower across all periods in GCS: the inequality level seems to increase across time, but with considerable differences across groups.

Figure 11 distinguishes the index dynamics in groups with differently generous $R$ (Non-Donor, Small Donor, or Substantial Donor, see Table 4). Clearly, a generous donor decreases the inequality index. In particular, the inequality index is rising for groups whose $R$ is rather opportunistic while it is stable across time when $R$ is a substantial donor.

\section{Conclusions}

Our testbed exploration of potential institutional alternatives does not exclude confounding effects, but only tries to limit and control them. From the perspective of experimental methodology, PCS and GCS do not qualify as treatments since they differ in more than one aspect: The effects of the institutional variations in our setup are confounded by changing both the number of voluntary contributors as well as the efficiency of contributing.

Our results nevertheless suggest to rely on GCS rather than PCS if these are the two options of a constitutional/institutional choice: Compared to PCS the institutional setting GCS enhances voluntary cooperation letting all endowment classes gain on average. The non-wealthy contribute more in GCS and only very few $R$-participants react to compulsory participation in non-discriminatory solidarity by neither contributing nor donating. $R$-members mostly retrieve costly information about individual contributions of the others and try to enhance their contributions by conditioning own contributions and donations on behavior of others. We also find that $R$-participants in GCS do not merely substitute donating by more efficient contributions but maintain retrieving information about contributions by the non-wealthy and use both mechanisms to improve the wellbeing of others in the group thereby reducing there potential resentment against supporting the "non-deserving".

We did not argue for or against compulsory solidarity nor did we discuss whether and when general compulsory solidarity is ethically, legally, or otherwise preferable. We have shown though that in our experimental setup GCS seems, economically and according to evaluative standards of customary morals, superior. We believe that the experiment raises interesting questions concerning the relation between non-discriminatory redistribution, as in unconditional basic income scheme favored

\footnotetext{
${ }^{15}$ We adopt the geometrical approach to compute the Gini index as the sum of the individual fraction geometrical areas in the unit box: each area is based on the wealth of the fraction of population considered and its "wealth ranking" among group members. See Xu (2003) for details on the different Gini index approaches.
} 
under principles of equal legal treatment, and discriminatory redistribution by targeted donations through private agents.

Acknowledgements Open access funding provided by Max Planck Society. This research project was financed by the Max Planck Institute for Research on Collective Goods. All errors are those of the authors. The authors gratefully acknowledge helpful comments by two referees and the constructive advice and help by the editor for revising the manuscript.

\section{Compliance with ethical standards}

Conflict of interest On behalf of all authors, the corresponding author states that there is no conflict of interest.

Open Access This article is licensed under a Creative Commons Attribution 4.0 International License, which permits use, sharing, adaptation, distribution and reproduction in any medium or format, as long as you give appropriate credit to the original author(s) and the source, provide a link to the Creative Commons licence, and indicate if changes were made. The images or other third party material in this article are included in the article's Creative Commons licence, unless indicated otherwise in a credit line to the material. If material is not included in the article's Creative Commons licence and your intended use is not permitted by statutory regulation or exceeds the permitted use, you will need to obtain permission directly from the copyright holder. To view a copy of this licence, visit http://creativecommons.org/licen ses/by/4.0/.

\section{Appendices}

\section{Appendix A: Instructions}

\section{Instructions to Participants (PCS)}

Introduction Welcome to our experiment!

During this experiment you will be asked to make several decisions, and so will the other participants. Your decisions, as well as the decisions of the other participants will determine your payoff according to rules, which will be explained below. What you earn during the experiment will be converted to euros at the rate of ECU (Experimental Currency Unit) $10 \mathrm{ECU}=80$ cent. In addition to the earnings from your decisions over the course of the experiment, you will receive a show-up fee of $€ 4.00$.

Please note that hereafter any form of communication between participants is strictly prohibited. If you violate this rule, you will be excluded from the experiment with no payment. If you have any questions, please raise your hand. The experimenter will come to you and answer your questions individually.

Description of the Experiment This experiment is fully computerized. The experiment has two phases (Phase 1, Phase 2). Each phase consists of 12 identical periods, in which you will be required to perform a Task as explained below.

During the experiment, groups of six participants will be randomly formed, and in every period of the same Phase you will be interacting with the same group of 
anonymous participants (how to interact with the others will be explained shortly). At the end of each phase, the computer will randomly form new groups.

Description of the Task At the beginning of the experiment, the computer will select your role. There are three possible roles; you can be $P$-type, $M$-type or $R$-type. Your role will never change during the experiment.

In each phase a group of 6 participants is formed: the group is formed by 1 $R$-type, $2 M$-type and $3 P$-type participants.

The task of each participant type is different:

- Description of the task for $P$

In each period, you and the other $P$-type individuals are endowed with 20 ECU.

$P$-type participants (and participants of $M$-type) of your group have to decide, individually and independently, how much of their endowment they want to contribute to a project (from 0 to $20 \mathrm{ECU}$ ).

Given the amount you contribute $c_{p}$, your payoff from the project is determined in each period according to the following formula:

$$
20-c_{p}+0.4 \text { (Total Contribution) }
$$

where Total Contribution is the sum of the individual contributions by three participants of $P$-type and two participants of $M$-type of your group; that is, Total Contribution $=c_{p 1}+c_{p 2}+c_{p 3}+c_{m 1}+c_{m 2}$.

After all participants decided on their contribution, the computer will inform you about the Total Contribution and your individual payoff.

- Description of the task for $M$

In each period, you and the other $M$-type individual are endowed with 60 ECU.

$M$-type participants (and participants of $P$-type) of your group have to decide, individually and independently, how much of their endowment they want to contribute to a project (from 0 to $20 \mathrm{ECU}$ ). This implies you cannot contribute your full endowment, but up to one-third of your total endowment.

Given the amount you contribute $c_{m}$, your payoff from the project is determined in each period according to the following formula:

$$
60-c_{m}+0.4 \text { (Total Contribution) }
$$

where Total Contribution $=c_{p 1}+c_{p 2}+c_{p 3}+c_{m 1}+c_{m 2}$.

After all participants decided on their contribution, the computer will inform you about the Total Contribution and your individual payoff.

- Description of the task for $R$

In each period, you are endowed with 560 ECU. 
Firstly, participants of $M$-type and participants of $P$-type of your group have to decide, individually and independently, how much of their endowment they want to contribute to a project.

After all participants decided on their contribution, the computer will communicate to you the Total Contribution to their project. The project result does not have any effect on your situation.

Secondly, a screen with five buttons appears on your screen; there are three buttons for $P$-types (button names are $c_{p 1}, c_{p 2}$ and $c_{p 3}$ ) and two buttons $M$-types (button names are $c_{m 1}$ and $c_{m 2}$ ). Each of the buttons represents a single information on that group member's individual contribution. You can decide to collect information about none/some/all individual contributions clicking on each button.

Retrieving the information is costly: each click on such a button costs you 10ECU.

After collecting information on other group members' contributions, a new screen will appear. Under each button, for each member of your group, there is an empty text cell, where you, $R$, can write for each group member, how much of your endowment you want to donate to that member.

You can donate from 0 to the maximum you are left with-after all your previous donations and information purchasing decisions-to a single participant. You cannot donate more than the ECU you are left with after purchasing information.

Your payoff is:

560-sum of information cost-sum of donations to group members.

Note that participants will be associated with the same name through the entire phase, so the button of $c_{p 1}$ always refers to the same participant in all periods of the same phase.

Information Feedback Before proceeding to the next period, the computer will inform each group member $P$ and $M$ about their final payoff, respectively the $R$-member about the final payoff and the sum of the project payoff plus donations.

- Summing up, your payoff for each period will depend: If you are $P$-type or $M$-type, on your initial decision to contribute and the donation received by the $R$-type participant;

- If you are the $R$-type, on the number of information retrievals you purchase and on donations to other group members.

End of the Experiment After completing the experiment, that is when the two phases will be over, a lottery administrated by the computer will randomly select one phase and one period of it to be considered for payment and will display on your screen the corresponding numerical payoff you made in that period.

Your total payoff from the experiment will be equal to the sum of:

- the payoff that you realized in the selected period of the selected phase.

- $€ 4$ of show up fee. 
A summary screen will display the total points you have accumulated and the corresponding earnings in euros. Please remain at your cubicle until asked to come forward and receive payment for the experiment. After having finished the experiment, but before receiving your payoff, you will be asked also to fill up a short questionnaire about your demographics and other few questions.

\section{Instructions to Participants (GCS)}

Introduction Welcome to our experiment!

During this experiment you will be asked to make several decisions, and so will the other participants. Your decisions, as well as the decisions of the other participants will determine your payoff according to rules, which will be explained below. What you earn during the experiment will be converted to euros at the rate of ECU (Experimental Currency Unit) $10 \mathrm{ECU}=80$ cent. In addition to the earnings from your decisions over the course of the experiment, you will receive a show-up fee of $€ 4.00$.

Please note that hereafter any form of communication between the participants is strictly prohibited. If you violate this rule, you will be excluded from the experiment with no payment. If you have any questions, please raise your hand. The experimenter will come to you and answer your questions individually.

Description of the Experiment This experiment is fully computerized. The experiment is composed of two phases (Phase 1, Phase 2). Each phase consists of 12 identical periods, in which you will be required to perform a task as explained below.

During the experiment, groups of six participants will be randomly formed, and in every period of the same Phase you will be interacting with the same group of anonymous participants (how to interact with the other will be explained shortly). At the end of each phase, the computer will randomly form new groups.

Description of the Task At the beginning of the experiment, the computer will select your role. There are three possible roles; you can be of $P$-type, $M$-type or $R$-type. Your role will never change during the experiment.

In each phase a group of six participants is formed: the group is formed by 1 $R$-type, $2 M$-type and $3 P$-type participants.

The task of each participant type is different:

- Description of the task for $P$

In each period, you and the other $P$-type individuals are endowed with 20 ECU.

$P$-type participants (and participants of $M$ - and $R$-type) of your group have to decide, individually and independently, how much of their endowment they want to contribute to a project (from 0 to $20 \mathrm{ECU}$ ). 
Given the amount you contribute $c_{p}$, your payoff from the project is determined in each period according to the following formula:

$$
20-c_{p}+0.4 \text { (Total Contribution) }
$$

where Total Contribution is the sum of the individual contributions by three participants of $P$-type, 2 participants of $M$-type and one participant of R type of your group; that is, Total Contribution $=c_{p 1}+c_{p 2}+c_{p 3}+c_{m 1}+c_{m 2}+c_{r}$.

After all participants decided on their contribution, the computer will inform you about the Total Contribution and your individual payoff.

\section{- Description of the task for $M$}

In each period, you and the other $M$ type individual are endowed with 60 ECU.

$M$-type participants (and participants of $P$ - and $R$-type) of your group have to decide, individually and independently, how much of their endowment they want to contribute to a project (from 0 to $20 \mathrm{ECU}$ ). This implies you cannot contribute your full endowment, but up to one-third of your total endowment.

Given the amount you contribute $c_{m}$, your payoff from the project is determined in each period according to the following formula:

$$
60-c_{m}+0.4 \text { (Total Contribution) }
$$

where Total Contribution $=c_{p 1}+c_{p 2}+c_{p 3}+c_{m 1}+c_{m 2}+c_{r}$.

After all participants decided on their contribution, the computer will inform you about the Total Contribution and your individual payoff.

- Description of the task for $R$

In each period, you are endowed with 560 ECU.

Firstly, participants of $R$-type (and participants $P$ - and $M$-type) of your group have to decide, individually and independently, how much of their endowment they want to contribute to a project (from 0 to $20 \mathrm{ECU}$ ). This implies you cannot contribute your full endowment.

Given the amount you contribute $c_{r}$, your payoff from the project is determined in each period according to the following formula:

$$
560-c_{r}+0.4 \text { (Total Contribution) }
$$

where Total Contribution $=c_{p 1}+c_{p 2}+c_{p 3}+c_{m 1}+c_{m 2+} c_{r}$.

After all participants decided on their contribution, the computer will inform you about the Total Contribution and your individual payoff.

Secondly, a screen with five buttons appears on your screen; there are three buttons for $P$-types (button names are $c_{p 1}, c_{p 2}$ and $c_{p 3}$ ) and two buttons for $M$-types (button names are $c_{m 1}$ and $c_{m 2}$ ). Each of the buttons represents a single information on that group member's individual contributions. You can decide to collect information about none/some/all individual contributions clicking on each button. 
Retrieving the information is costly: each click on such a button costs you 10 ECU.

After collecting information on other group members contributions, a new screen will appear. Under each button, for each member of your group, there is an empty text cell, where you, $R$, can write for each group member, how much of your endowment you want to donate to that member.

You can donate from 0 to the maximum you are left with-after all your previous donations and information purchasing decisions - to a single participant. You cannot donate more than the ECU you are left with after purchasing information.

Your payoff is:

$560-c_{r}+0.4$ (Total Contribution) - sum of information cost - sum of donations to group members Note that participants will be associated with the same name through the entire phase, so the button of $c_{p 1}$ always refers to the same participant in all periods of the same phase.

Information Feedback Before proceeding to the next period, the computer will inform each group member $P$ and $M$ about their final payoff, respectively the $R$-members about the sum of the project payoff plus donations.

Summing up, your payoff for each period will depend:

If you are $P$-type or $M$-type, on your initial decision to contribute and the donation received by $R$-type participant;

- If you are the $R$-type, on your initial decision to contribute, on the number of information retrievals you purchase, and on donations to other group members.

End of the Experiment After completing the experiment, that is when the two phases will be over, a lottery administrated by the computer will randomly select one phase and one period of it to be considered for payment and will display it on your screen the corresponding numerical payoff you made in that period.

Your total payoff from the experiment will be equal to the sum of:

- the payoff that you realized in the selected period of the selected phase

- $€ 4$ of show up fee.

A summary screen will display the total points you have accumulated and the corresponding earnings in euros. Please remain at your cubicle until asked to come forward and receive payment for the experiment. After having finished the experiment, but before receiving your payoff, you will be asked also to fill up a short questionnaire about your demographics and other few questions.

\section{Appendix B: Tables and Figures}

See Figs. 12, 13; Tables 7, 8 and 9. 


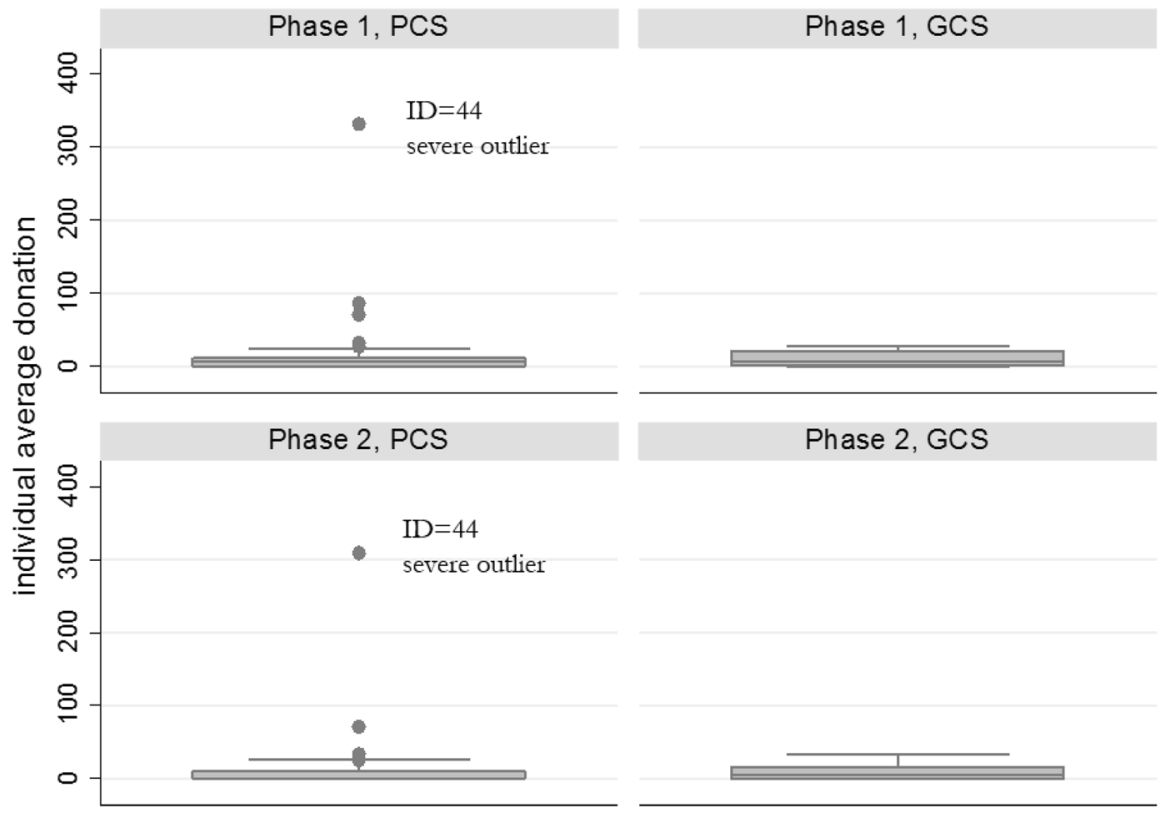

Fig. 12 Average individual donation by phase and condition

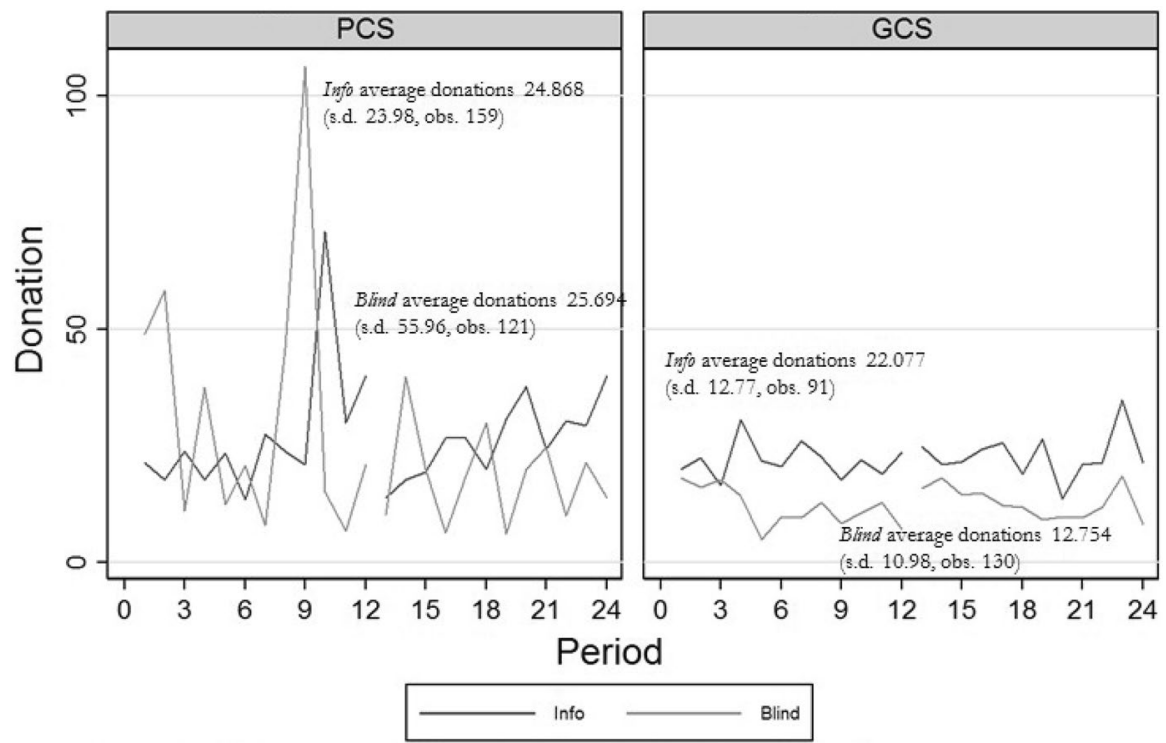

Fig. 13 Average (positive) donation by blind and non-blind $R$-participants. We include the wealthy which have donated at least one ECU to at least one member of the group 


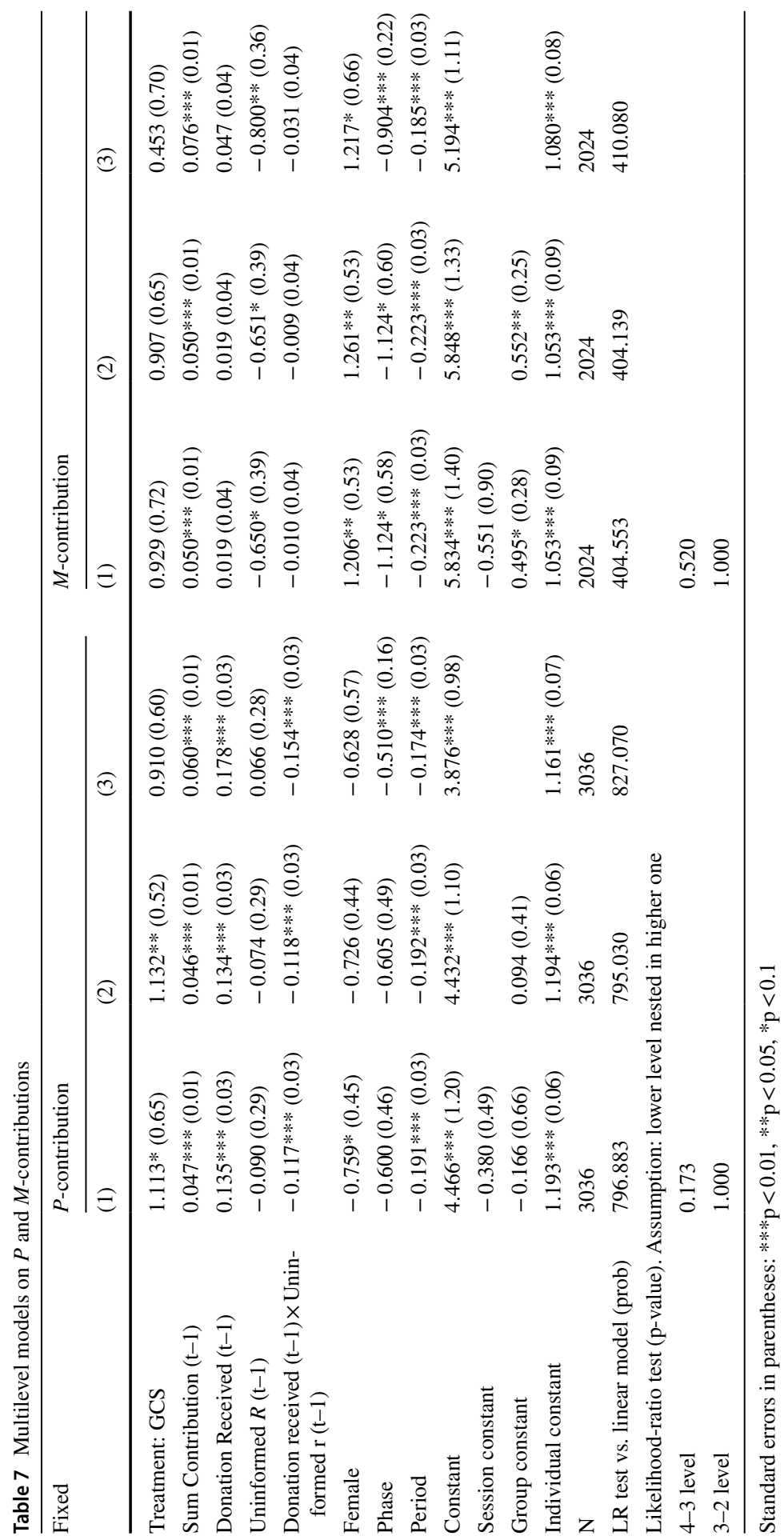


Table 8 Multilevel models on $R$-donations

\begin{tabular}{llll}
\hline Fixed & \multicolumn{2}{l}{ Dependent: $R$-donation } & \\
\cline { 2 - 4 } & $(1)$ & $(2)$ & $(3)$ \\
\hline Own contribution & $0.203^{* * *}(0.07)$ & $0.203 * * *(0.07)$ & $0.170^{* *}(0.07)$ \\
Donation (t-1) & $0.512^{* * *}(0.04)$ & $0.512^{* * *}(0.04)$ & $0.441^{* * *}(0.04)$ \\
\# Information acquired & $0.344 * * *(0.04)$ & $0.344 * * *(0.04)$ & $0.336^{* * *}(0.04)$ \\
Female & $-0.231(0.89)$ & $-0.231(0.89)$ & $-0.446(1.42)$ \\
Phase & $1.422^{*}(0.82)$ & $1.422^{*}(0.82)$ & $1.146(0.81)$ \\
Period & $-0.146(0.13)$ & $-0.146(0.13)$ & $-0.193(0.13)$ \\
Constant & $-0.525(1.77)$ & $-0.525(1.77)$ & $1.307(1.91)$ \\
Session constant & $-16.163(12.50)$ & & \\
Group constant & $-12.623(921.81)$ & $-21.901(1581.03)$ & \\
Individual constant & $-12.623(920.86)$ & $-21.367 * * *(3.98)$ & $0.730^{*}(0.38)$ \\
$\mathrm{N}$ & 352 & 352 & 352 \\
LR test vs. linear model (prob) & 0.000 & 0.000 & 4.031 \\
Likelihood-ratio test (p value). Assumption: lower level nested in higher one & \\
4-3 level & 1.000 & & \\
3-2 level & 1.000 & & \\
\hline
\end{tabular}

Standard errors in parentheses: ***p $<0.01, * * \mathrm{p}<0.05, * \mathrm{p}<0.1$

Table 9 Multilevel models $R$-contributions

\begin{tabular}{llll}
\hline Fixed & \multicolumn{4}{l}{ Dependent: $r$-contribution in GCS } & $(3)$ \\
\cline { 2 - 4 } & $(1)$ & $(2)$ & $0.148^{* * *}(0.05)$ \\
\hline Own contribution (t-1) & $0.075(0.05)$ & $0.066(0.05)$ & $0.222^{* * *}(0.03)$ \\
Donation (t-1) & $0.220^{* * *(0.03)}$ & $0.206 * * *(0.03)$ & $-0.045(0.03)$ \\
\# Information acquired (t-1) & $-0.025(0.03)$ & $-0.023(0.03)$ & $2.042(1.32)$ \\
Female & $2.617 * *(1.27)$ & $2.181^{*}(1.27)$ & $-1.865^{* * *}(0.61)$ \\
Phase & $-1.962 *(1.04)$ & $-2.008^{*}(1.18)$ & $0.009(0.09)$ \\
Period & $0.012(0.09)$ & $0.005(0.09)$ & $6.880^{* * *}(1.51)$ \\
Constant & $7.304 * * *(2.05)$ & $7.763 * * *(2.13)$ & \\
Session constant & $0.342(0.56)$ & & $0.755^{* * *}(0.26)$ \\
Group constant & $0.532(7.83)$ & $0.717(21.94)$ & 352 \\
Individual constant & $0.532(7.83)$ & $0.717(21.94)$ & 14.773 \\
$\mathrm{~N}$ & 352 & 352 & \\
LR test vs. linear model (prob) & 19.026 & 16.787 & \\
Likelihood-ratio test (p-value). Assumption: lower level nested in higher one \\
4-3 level
\end{tabular}

Standard errors in parentheses. $* * * \mathrm{p}<0.01, * * \mathrm{p}<0.05, * \mathrm{p}<0.1$ 


\section{References}

Alesina, A., \& La Ferrara, E. (2000). Participation in heterogeneous communities. The Quarterly Journal of Economics, 115(3), 847-904.

Andreoni, J., Harbaugh, W., \& Vesterlund, L. (2003). The carrot or the stick: Rewards, punishments, and cooperation. American Economic Review, 93(3), 893-902.

Arellano, M., \& Bond, S. (1991). Some tests of specification for panel data: Monte carlo evidence and an application to employment equations. The Review of Economic Studies, 58(2), 277-297.

Bekkers, R., \& Wiepking, P. (2011). A literature review of empirical studies of philanthropy: Eight mechanisms that drive charitable giving. Nonprofit and Voluntary Sector Quarterly, 40(5), 924-973.

Blanco, E., Lopez, M.C., \& Coleman, E.A. (2012). Voting for environmental donations: Experimental evidence from Majorca, Spain. Ecological Economics, 75, 52-60.

Bolton, G.E., Katok, E., \& Zwick, R. (1998). Dictator game giving: Rules of fairness versus acts of kindness. International Journal of Game Theory, 27(2), 269-299.

Buchanan, J.M., \& Congleton, R.D. (2006). Politics by principle, not interest: Towards nondiscriminatory democracy. Cambridge: Cambridge University Press.

Buckley, E., \& Croson, R. (2006). Income and wealth heterogeneity in the voluntary provision of linear public goods. Journal of Public Economics, 90(4-5), 935-955.

Cason, T.N., \& Khan, F.U. (1999). A laboratory study of voluntary public goods provision with imperfect monitoring and communication. Journal of Development Economics, 58(2), 533-552.

Chan, K., Mestelman, S., Moir, R., \& Muller, R. (1996). The voluntary provision of public goods under varying income distributions. The Canadian Journal of Economics/Revue Canadienne D’Economique, 29(1), 54-69. https://doi.org/10.2307/136151.

Chowdhury, S.M., \& Jeon, J.Y. (2014). Impure altruism or inequality aversion?: An experimental investigation based on income effects. Journal of Public Economics, 118, 143-150.

Eckel, C.C., \& Grossman, P.J. (1996). Altruism in anonymous dictator games. Games and Economic Behavior, 16(2), 181-191.

Engel, C. (2011). Dictator games: A meta study. Experimental Economics, 14(4), 583-610.

Engelmann, D., \& Strobel, M. (2004). Inequality aversion, efficiency, and maximin preferences in simple distribution experiments. American Economic Review, 94(4), 857-869. https://doi. org/10.1257/0002828042002741.

Engelmann, D., \& Strobel, M. (2007). Preferences over income distributions: Experimental evidence. Public Finance Review, 35(2), 285-310.

Fehr, E., \& Gächter, S. (2000). Fairness and retaliation: The economics of reciprocity. Journal of Economic Perspectives, 14(3), 159-181.

Fehr, E., \& Gächter, S. (2002). Altruistic punishment in humans. Nature, 415(6868), 137.

Fischbacher, U. (2007). Z-tree: Zurich toolbox for ready-made economic experiments. Experimental Economics, 10(2), 171-178.

Forsythe, R., Horowitz, J.L., Savin, N.E., \& Sefton, M. (1994). Fairness in simple bargaining experiments. Games and Economic Behavior, 6(3), 347-369.

Friedman, M. (1962). Capitalism and freedom university of Chicago Press. Chicago: University of Chicago.

Greiner, B. (2015). Subject pool recruitment procedures: Organizing experiments with ORSEE. Journal of the Economic Science Association, 1(1), 114-125.

Isaac, R.M., \& Walker, J.M. (1988). Group size effects in public goods provision: The voluntary contributions mechanism. The Quarterly Journal of Economics, 103(1), 179-199.

Kachelmeier, S., \& Shehata, M. (1997). Internal auditing and voluntary cooperation in firms: A crosscultural experiment. The Accounting Review, 72(3), 407-431. Retrieved from https://www.jstor.org/ stable/248478.

Keser, C., Markstädter, A., \& Schmidt, M. (2017). Mandatory minimum contributions, heterogeneous endowments and voluntary public-good provision. Games and Economic Behavior, 101, 291-310.

Kliemt, H. (1993). On justifying a minimum welfare state. Constitutional Political Economy, 4(2), $159-172$.

Kölle, F. (2015). Heterogeneity and cooperation: The role of capability and valuation on public goods provision. Journal of Economic Behavior \& Organization, 109, 120-134.

List, J.A. (2007). On the interpretation of giving in dictator games. Journal of Political Economy, 115(3), $482-493$. 
Mackie, J.L. (1982). Morality and the retributive emotions. Criminal Justice Ethics, 1(1), 3-10.

Masclet, D., Noussair, C., Tucker, S., \& Villeval, M.-C. (2003). Monetary and nonmonetary punishment in the voluntary contributions mechanism. American Economic Review, 93(1), 366-380.

Mikula, G. (1972). Gewinnaufteilungsverhalten in Dyaden Bei Variiertem Leistungsverhältnis. Zeitschrift Für Sozialpsychologie, 3, 126-133.

Moffatt, P.G. (2015). Experimetrics: Econometrics for experimental economics. Macmillan International Higher Education.

Oprea, A. (2019). Democracy as a game of trust: The limits of generality constraints. Homo Oeconomicus. https://doi.org/10.1007/s41412-019-00092-7.

Plott, C.R. (1997). Laboratory experimental testbeds: Application to the PCS auction. Journal of Economics \& Management Strategy, 6(3), 605-638.

Reuben, E., \& Riedl, A. (2009). Public goods provision and sanctioning in privileged groups. Journal of Conflict Resolution, 53(1), 72-93.

Reuben, E., \& Riedl, A. (2013). Enforcement of contribution norms in public good games with heterogeneous populations. Games and Economic Behavior, 77(1), 122-137.

Roth, A.E., \& Sotomayor, M. (1992). Two-sided matching. Handbook of Game Theory with Economic Applications, 1, 485-541.

Sefton, M., Shupp, R., \& Walker, J.M. (2007). The effect of rewards and sanctions in provision of public goods. Economic Inquiry, 45(4), 671-690.

Selten, R., \& Ockenfels, A. (1998). An experimental solidarity game. Journal of Economic Behavior \& Organization, 34(4), 517-539.

Shapiro, E.G. (1975). Effect of expectations of future interaction on reward allocations in dyads: Equity or equality. Journal of Personality and Social Psychology, 31(5), 873.

Smith, A. (2011). Group composition and conditional cooperation. The Journal of Socio-Economics, 40(5), 616-622.

Sutter, M., Haigner, S., \& Kocher, M.G. (2010). Choosing the carrot or the stick? Endogenous institutional choice in social dilemma situations. The Review of Economic Studies, 77(4), 1540-1566.

Van Parijs, P. (1992). Arguing for basic income (Vol. 995). London: Verso.

Wiepking, P., \& Bekkers, R. (2012). Who gives? A literature review of predictors of charitable giving. Part two: Gender, family composition and income. Voluntary Sector Review, 3(2), 217-245.

$\mathrm{Xu}, \mathrm{K}$. (2003). How has the literature on gini's index evolved in the past 80 years. China Economic Quarterly, 3, 000 .

Publisher's Note Springer Nature remains neutral with regard to jurisdictional claims in published maps and institutional affiliations. 